\section{Self-expandable metal stents placed with overtube for the treatment of malignant obstruction of the gastrointestinal tract in 33 consecutive patients}

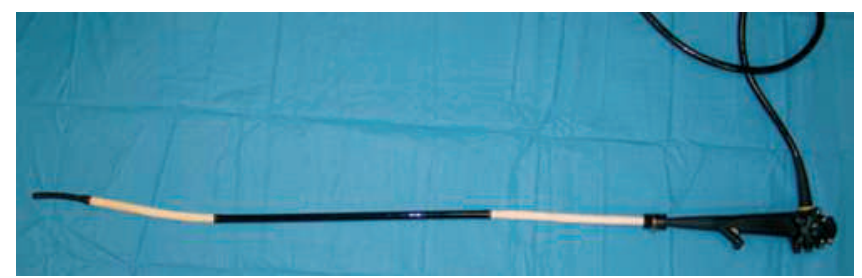

Figure 1 Standard gastroscope through the overtube.

The insertion of expandable metallic stents has become the treatment of choice for patients with a neoplastic obstruction of the digestive tract that is considered to be unresectable [1]. If techniques for insertion of metallic stents are well established, the insertion of a metallic stent in distal sites, especially in the antrum or duodenum is more difficult [2,3]. We present a series of patients treated by self-expandable metal stents placed with an overtube.

A standard gastroscope (Olympus GIF145) was inserted through the overtube (Olympus, ST-S2, external diameter of $1.5 \mathrm{~cm}$ ) (Figure 1). Both overtube and gastroscope were introduced until they reached either the neoplasm stenosis, or the most distal part of the digestive tract. We injected contrast media through a double-lumen catheter on a stiff guide wire. The proximal and distal parts of the stenosis were identified. Another stiff guide wire (Wallstent Superstiff $>4.5 \mathrm{~m}$ of size, Boston Scientific, ref. H9651800010 or Zebra, Boston Scientific, ref. 5168-01) was inserted through the stenotic region. The guide wire was left in place and the gastroscope was removed. Next, the stent system (Boston Scientific, Wallstent Enteral Endosprosthesis) was inserted through the overtube, and over the guide wire (Figure 2 ). Detachment of the stent was performed under fluoroscopic control.
Between September 2002 and December 2004, 33 consecutive patients with a median age of 66 years (range $32-87$ ) were treated by this technique. Stenoses were located: on proximal duodenal in eight patients, on D2 or genu superius in 15 patients, on angle of Treitz in five patients, on distal colon in four patients, and on proximal colon in one patient.

The procedure was successful in 32 (97\%) patients. There was no procedure-related mortality.

In summary, the interest of this technique lies in the use of a standard endoscope through an overtube. This procedure with endoscopic and fluoroscopic guidance is feasible, simple, and cheap.

Endoscopy_UCTN_Code_TTT_1AO_2AZ

\section{E. Samalin', E. Assenat', P. Bauret², \\ P. Senesse ${ }^{1}$}

${ }^{1}$ Department of Nutrition and Digestive Oncology, Val d'Aurelle Cancer Institute, Montpellier, France

2 Department of Gastroenterology, SaintEloi Hospital, Montpellier, France.

\section{References}

${ }^{1}$ Maetani I, Tada T, Ukita T et al. Comparison of duodenal stent placement with surgical gastrojejunostomy for palliation in patients with duodenal obstructions caused by pancreaticobiliary malignancies. Endoscopy 2004; 36: 73-78

${ }^{2}$ Baron T. Expandable metal stents for the treatment of cancerous obstruction of the gastrointestinal tract. N Engl J Med 2001; 344: $1681-1687$

${ }^{3}$ Maetani I, Ukita T, Inone $\mathrm{H}$ et al. Knitted nitinol stent insertion for various intestinal stenoses with modified delivery system. Gastrointest Endosc 2001; 54: $364-367$
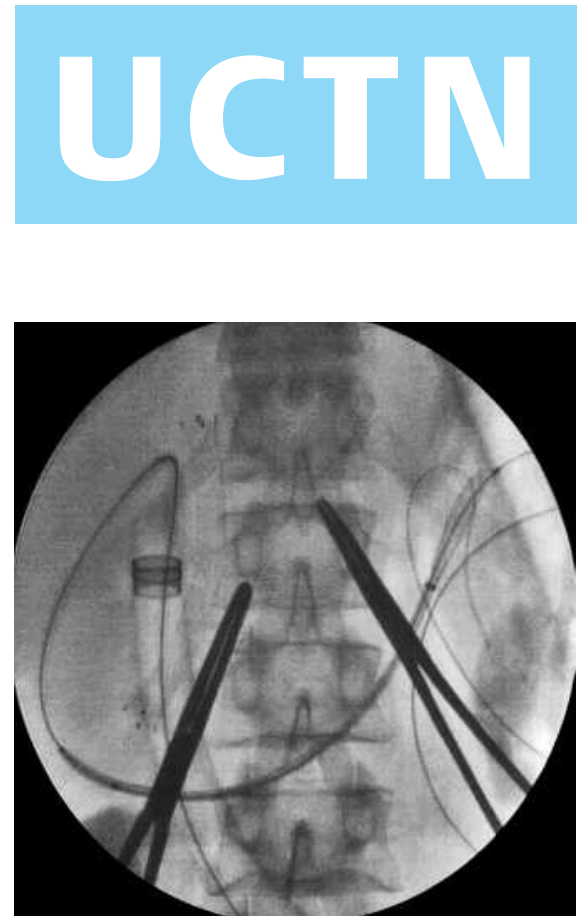

Figure 2 Guide wire, overtube, and stent under fluoroscopic control.

\section{Corresponding author}

\section{P. Senesse, PhD}

Département de Nutrition et Oncologie Digestive

Val d'Aurelle Cancer Institute

Rue de la Croix Verte

34298 Montpellier

Cedex 5

France

Fax: +33-467-613733

Email: psenesse@valdorel.fnclcc.fr 